\title{
Mathematical Modeling of Hidden Intimate Partner Violence in Spain: A Quantitative and Qualitative Approach
}

\author{
E. De la Poza, ${ }^{1}$ L. Jódar, ${ }^{2}$ and S. Barreda ${ }^{2}$ \\ ${ }^{1}$ Centro de Ingeniería Económica, Faculty of Business and Management, Universitat Politècnica de València, 46022 València, Spain \\ ${ }^{2}$ Instituto Universitario de Matemática Multidisciplinar, Universitat Politècnica de València, 46022 València, Spain
}

Correspondence should be addressed to E. De la Poza; elpopla@esp.upv.es

Received 14 July 2016; Accepted 13 October 2016

Academic Editor: Ivan Ivanov

Copyright (C) 2016 E. De la Poza et al. This is an open access article distributed under the Creative Commons Attribution License, which permits unrestricted use, distribution, and reproduction in any medium, provided the original work is properly cited.

\begin{abstract}
The fact that women are abused by their male partner is something that happens worldwide in the 21st century. In numerous cases, abuse only becomes publicly known when a fatal event occurs and is beyond any possible remedy, that is, when men murder their female partner. Since 2003, 793 (September 4, 2015) women have been assassinated by their significant other or excouple in Spain. Only 7.2\% of murdered women had reported their fear and previous intimate partner violence (IPV) to the police. Even when the number of female victims is comparable to the number of victims by terrorism, the Government has not assigned an equal amount of resources to diminish the magnitude of this hidden social problem. In this paper, a mathematical epidemiological model to forecast intimate partner violence in Spain is constructed. Both psychological and physical aggressor subpopulations are predicted and simulated. The model's robustness versus uncertain parameters is studied by a sensitivity analysis.
\end{abstract}

\section{Introduction}

Violence against women occurs in all geographical areas and in all types of society. Violence affects girls and women of all ages and in all stages of life. In western societies, it has not been until quite recently (1979) that the intimate violence partner was institutionally identified and condemned. The origin is found in feminists in the 1950s [1].

Women abuse embraces different types of manifestations, such as physical violence, including sexual abuse, emotionalpsychological violence, verbal abuse, religious discrimination, economic deprivation, isolation, gender privilege, and beating [2].

Women abuse takes place in different environments: workplace, public areas, family, and friends, and even at continuous and sustained connectability due to technological appliances. While the former type (workplaces and public areas) is more visible and socially condemned $[3,4]$, violence that occurs in families, particularly intimate violence partner, is hidden $[5,6]$ and linked to drunkenness and drug consumption causes [7].

Moreover according to [8] women, the risk of suffering abuse or being raped in an age interval $[15,44]$ is higher than the risk of suffering cancer, malaria, or a car accident [9].
According to [8], as many as $38 \%$ of all women murders are committed by their intimate partners.

The incidence of violence against women in intimate relationships is difficult to diagnose. In fact, five different types can be identified: coercive controlling, violent resistance, situational couple violence, separation-instigated violence, and mutual violent control [10]. Intimate partner violence occurs in all settings and in all socioeconomic, religious, and cultural groups. Indeed the commonest perpetrators of violence against women are male intimate partners or expartners [11, 12].

Even when progress is made from the justice viewpoint, the intimate violence problem remains mainly hidden for several reasons, such as low victimization acceptance, as it takes place at the heart of the couple. It produces social shame and a feeling of emotional failure experienced by women, which are the strength of a male chauvinist culture. There is also common victim tendency to forgive and forget lower levels of violence based on the myth of the romantic love that causes intimate partner violence (IPV) to persist [13]. Furthermore in those cases in which women recognize themselves as victims, lack of immediate public protocols reduces the number of legal complaints about victims' insecurity [14]. 
It is difficult not only to identify the IPV problem, but to also quantify it in order to strength the claim for public answers to mitigate this social problem. In fact, the only available information is the casualties and police complaints made by victims [15], mostly when couples have broken up in practice, but not officially/socially. In fact, abused women who leave their couples are at more risk of lethal violence than those who do not [16].

As far as we know, previous studies have been qualitative in nature, have been based on sampling women populations by questionnaires [17], or have conducted research by focusing on abused women once they have recovered [18].

For the particular case of Spain, more than 1,000 women have been murdered in the last 15 years by their significant others, a number that exceeds the number of victims murdered by the terrorist group ETA. For the time being, about 4,500 aggressors are in Spanish prisons for committing sexual abuse [19].

There exist recent studies modeling mathematically the domestic violence throughout continuous time differential equation models $[20,21]$. However, domestic violence embraces all types of aggressions occurring in the family unit, including violence against children, while intimate partner violence only embraces aggressions among couples. Furthermore, the models developed at $[20,21]$ are not realistic in the sense that those assume the propagation depends on the proportion of victims. Also, those studies do not take into account demographics or socioeconomic factors.

The aim of this paper was to construct a dynamic mathematical model by forecasting the amount of intimate partner aggressors over the 2012-2017 time horizon in Spain. By means of a population model that split the population into several categories according to different levels of violence and by quantifying by semester the main causes of IPV transits among subpopulations, a difference system provided dynamic quantification in a future time.

This paper is structured as follows: Section 2 shows the hypotheses and model construction; Section 3 illustrates the results and simulation; Section 4 summarizes the conclusions and provides recommendations for short- and long-term reductions of the intimate partner violence (IPV) problem.

\section{Hypotheses and Model Construction}

Violence against women is transversal, with no distinction of social class or academic and professional qualification. We split the population of potential men abusers in Spain whose ages fell in the interval $[16,74]$ into four compartments according to the level of violence committed against their heterosexual couples. Depending on an increasing degree of violence, the categories were defined as follows.

Gender Egalitarian Man. A category defined as men free of sexist microaggressions. Relationships with gender egalitarian man are characterized by flexibility and negotiability of gender roles, with the primary goal of satisfying individual needs [22].
Regular Men. A subpopulation defined by men influenced by a generalized male chauvinist environment since they could practice sexist microaggression, such as verbal joking without committing either psychological or physical aggression against their couple.

Emotional-Psychological Abuser. A category that embraces those men who attempt to control and reduce their couples' freedom by attacking her self-esteem [16].

Physical Aggressor. A category that includes those men who use physical force against their partner, including undesired sexual relationships [16].

Our study started in January 2012 and split the male population in Spain by semester into the four above-defined categories using the following notation:

$S(n)$ : gender egalitarian men at semester $n(n=0$ corresponds to January 2012)

$N(n)$ : regular men at semester $n$

AS $(n)$ : emotional-psychological abuser men at semester $n$

$\operatorname{AF}(n)$ : physical aggressor men at semester $n$

The male population whose ages fell in the interval $[16,74]$ at the beginning of the study (January 2012) came to $16,794,613$. We began quantifying subpopulation $\mathrm{AF}(0)$, obtained by the number of legal complaints for gender violence registered by [23], in addition to the number of murdered women who had not previously complained, which came to 134,048 women, which represents $0.8 \%$ of the total male population in January 2012 [24]. This amount underestimated the unknown real number of AF aggressors because those women had not legally complained [25].

Secondly, we estimated the AS subpopulation following [26] and sizing the proportion as $36 \%$ of the total male population.

The $S$ subpopulation was estimated following [27] by quantifying the proportion of this category as $10.20 \%$ of the total male population.

Finally by subtracting the amounts of the three previous categories from the general population, we estimated the number of regular men $(N(0))$ as being $53 \%$ of the population, which comes close to 9 million men (8,901,145 men; see Table 1).

Among the factors that influence human behavior, we consider demographic, economic, and psychosocial factors. Some other possible factors are of the genetic type, which was not taken into account $[28,29]$. The legal factor was not considered because the legal conditions did not change during the study period.

Our dynamic compartmental model was built by quantifying the semester transits between subpopulations throughout the study period (January 2012-December 2017).

We defined and quantified these transit coefficients. Changes in total population were due to demographic factors, in particular, birth (men who became 16 years old), death (naturally deceased or functional exit from the system 
TABLE 1: Initial subpopulation in January 2012.

\begin{tabular}{lccc}
\hline$S(0)=r_{1}$ & $N(0)=r_{2}$ & $\mathrm{AS}(0)=r_{3}$ & $\mathrm{AF}(0)=r_{4}$ \\
\hline $10.20 \%$ & $53 \%$ & $36 \%$ & $0.8 \%$ \\
\hline
\end{tabular}

TABLE 2: Subpopulation proportions of model incomers.

\begin{tabular}{lc}
\hline Egalitarian & $5.00 \%$ \\
Regular & $58.57 \%$ \\
Emotional-psychological abuser & $33.00 \%$ \\
Physical aggressor & $3.43 \%$ \\
\hline
\end{tabular}

when men became older than 75 years old), and emigration/immigration.

By obtaining the number of male births at each semester [30], we distributed these data among the subpopulations and according to the proportions that resulted from [31] (Table 2). We assumed that these proportions remained constant for the short study period. This coefficient was denoted by

$$
\alpha_{i}(n-32), \quad 1 \leq i \leq 4,
$$

where $\alpha_{i}(n-32)$ represents the number of males born 16 years ago (32 semesters).

This proportion in absolute values sized the quantities shown in Table 3.

Leaving the system occurred when the population became older than 74 years but also when males died in the age interval $[16,74]$. The total number of outcomers was distributed into the subpopulations according to their proportional size in 2012, $1 \leq i \leq 4$, by assuming that probability of death was exactly the same among all the subpopulations. In both cases, we assumed that these proportions remained constant for the short study period considered. This coefficient is denoted as $D_{i}, 1 \leq i \leq 4$ [30].

Finally, the last demographic transit results from the net emigration impact due to economic reasons [32]. In line with the deterioration of the Spanish economy (high unemployment rate, deterioration of the welfare system) from January 2012 to December 2014, a significant proportion of the Spanish population emigrated abroad to seek work. This process stopped in January 2015 due to an initial recovery of the Spanish economy. Thus we assumed that the net emigration factor due to economic reasons had disappeared since January 2015. We also assumed that the probability of emigration was the same in the four categories and that the number of emigrants was sized according to the 2012 proportion of each subpopulation. According to these data and hypotheses, the emigration coefficient was quantified as follows:

$$
\begin{aligned}
& \gamma_{1 r_{i}(n)} \\
& = \begin{cases}113203 * r_{i} ; & 1 \leq i \leq 4, n=0,1 \quad(2012) \\
131204 * r_{i} ; & 1 \leq i \leq 4, n=2,3 \quad(2013) \\
49736 * r_{i} ; & 1 \leq i \leq 4, n=4,5 \quad(2014) \\
0 ; & 11 \geq n \geq 6 \quad(2015,2016,2017),\end{cases}
\end{aligned}
$$

TABLE 3: Number of model incomers per semester.

\begin{tabular}{lcccc}
\hline & $S$ & $N$ & AS & AF \\
\hline 01-Jul-12 & 4,667 & 54,675 & 30,805 & 3,202 \\
01-Jan-13 & 4,753 & 55,674 & 31,368 & 3,260 \\
01-Jul-13 & 4,753 & 55,674 & 31,368 & 3,260 \\
01-Jan-14 & 4,725 & 55,348 & 31,185 & 3,241 \\
01-Jul-14 & 4,725 & 55,348 & 31,185 & 3,241 \\
01-Jan-15 & 4,894 & 57,323 & 32,297 & 3,357 \\
01-Jul-15 & 4,894 & 57,323 & 32,297 & 3,357 \\
01-Jan-16 & 5,140 & 60,209 & 33,923 & 3,526 \\
01-Jul-16 & 5,140 & 60,209 & 33,923 & 3,526 \\
01-Jan-17 & 5,220 & 61,143 & 34,450 & 3,581 \\
01-Jul-17 & 5,220 & 61,143 & 34,450 & 3,581 \\
\hline
\end{tabular}

where $r_{i}$ is the proportion of each subpopulation estimated in January 2012 (see Table 1).

Apart from the demographic factors, the subpopulations' dynamical behavior was influenced by the following.

(I) Women's level of permissiveness against abusive behavior by their partners $[33,34]$.

(II) Men's alcohol and drug consumption [7, 35].

(III) Jealousy as a factor promoted by the chauvinist culture [34].

(IV) Economic stress (long-term unemployment) [30].

(V) The contagion effect on men caused by their close environment where examples of gender violence are experienced or suffered throughout $[16,36]$.

(VI) Technology: the impact of new technologies on intimate partner psychological abuse (stalking) [37].

After we identified the main factors that influenced the intimate violence partners phenomenon, we proceeded to quantify the transit coefficients among categories from one period $(n)$ to the next $(n+1)$.

We began by measuring the transit from the subpopulation of regular $N(n)$ to $S(n+1)$.

We assumed that this effect occurred only after a stable relationship among young partners. In our hypotheses, this possibility only occurred in a stable relationship between a young regular $(N)$ nonjealous man and an egalitarian young woman who did not accept any kind of sexual microaggression. We assumed that the successful transit occurred with a probability of $1 / 4$. This coefficient remained constant throughout the short study period and was computed as follows:

$\beta_{1}=$ (proportion of men whose ages fell in the interval $[16,35]) *$ (proportion of nonjealous men) * (proportion of egalitarian women $)=0.35 * 0.30 * 0.30 * 1 / 4=0.007875$.

2.1. Transit from $N$ to the AS Subpopulation. $\beta_{2}=$ (proportion of jealous men who consumed drugs and/or alcohol in a stable relationship with a nonegalitarian woman per semester) $=1 / 2 * 0.7 *(0.05+0.0 E) *(0.7)=0.01225+0.00245 E$, where $E$ is a perturbation coefficient due to the difficulty of 


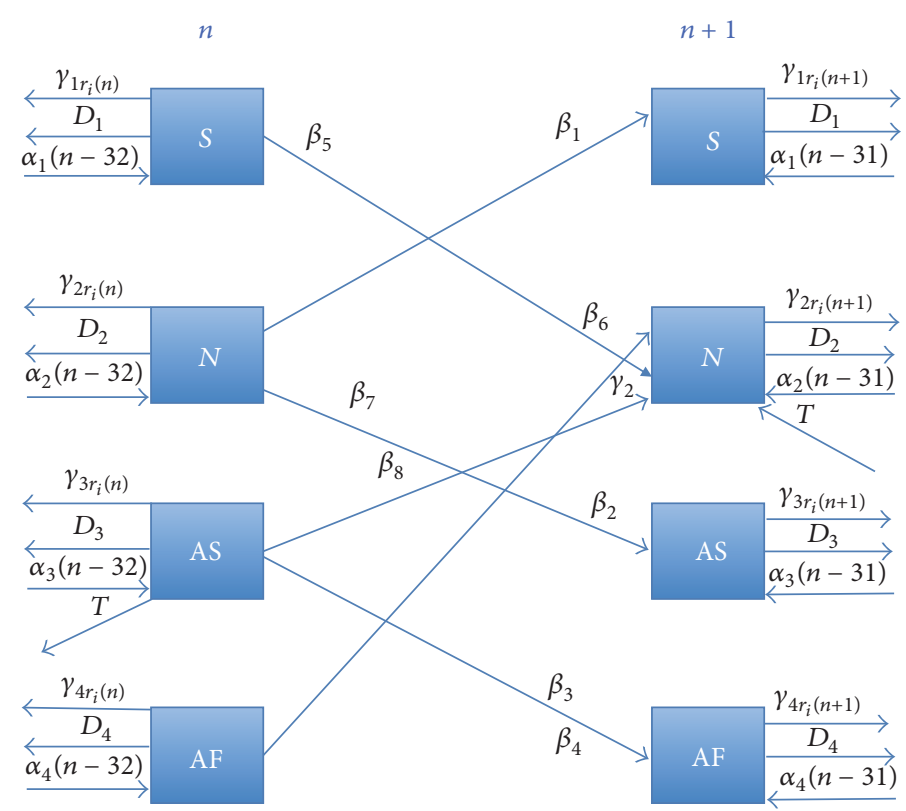

Figure 1: Block diagram model.

measuring the real proportion of consumers of drugs/alcohol. We assumed the variation range of $E$ in the interval $[0,2]$, which means that we considered a perturbation of the coefficient of $2 \%$ at the most $[33,35]$.

2.2. Transits from the AS to the AF Subpopulation. There were two independent and different types of transit among the same subpopulations.

$\beta_{3}=$ (proportion of men consumers of drugs/alcohol in a stable relationship per semester $)=0.105 / 2=0.0525$ [35].

$\beta_{4}=$ (proportion of men whose relationship broke up, combined with long-term unemployment or consumed drugs/alcohol per semester $)=1 / 2 *[(0.5 * 0.27 * 0.02)+$ $(0.5 *(0.05+0.0 E))]=0.026+0.025 E[30,34]$.

2.3. Transit from $S$ to the $N$ Subpopulation. $\beta_{5}=6$-monthly proportion of men in a relationship with a nonegalitarian woman transiting after a broken relationship due to the infidelity effect $=(1 / 2) *(0.7 * 0.174 * 0.5)=0.03045$ [37].

2.4. Transit from the AF to the N Subpopulation. We considered the recovery effect due to therapy and the positive influence of a new egalitarian partner woman.

$\beta_{6}=6$-monthly proportion of separated or divorced men who engaged in a new relationship with an egalitarian woman, in addition to the separated men under 50 years of age who engaged in a new relationship with nonegalitarian women who attended therapy [16] per semester $=(1 / 2) *$ $[(0.5 * 0.3)+(0.5 * 0.7 * 0.05 * 0.55)]=0.08375$.

2.5. Transit from the AS to the N Subpopulation. $\gamma_{2}=6$ monthly proportion of men whose ages fell in the interval
$[16,35]$ and who started a stable relationship with an egalitarian woman for at least 1 year:

$$
\gamma_{2}=\frac{1}{2}(0.35 * 0.3 * r)=0.0525 * r
$$

where $r$ is the probability of the couple lasting. We simulated different values for $r$ in the interval $=i / 8$, where $i$ varied from 1 to 8 .

$T=$ the number of males that attend therapy (cognitive behavioral therapy, psychodynamic therapy) transiting from AS to $N . T=600$. This amount is considered constant for the period of study [38].

2.6. Transit from $N$ to the AS Subpopulation. $\beta_{7}=$ proportion of psychopathic men $(1 \%)=0.01$. This transit was constant and occurred for genetic reasons [39, 40].

$\beta_{8}=$ proportion of jealous men whose ages fell in the interval $[16,40]$ in a relationship with a nonegalitarian woman who used technology [40] as the channel to exercise control aggression with their couples. For instance, frequent communication throughout calls and messages in attempt to forbid or persuade a particular behavior and to remain in control [8, 37, 41, 42], quantified approximately as follows: $\beta_{8}=$ technology factor $(\mathrm{TF}) *$ proportion of jealous men $*$ proportion of men younger than 40 years $*$ proportion of nonegalitarian women $=\mathrm{TF} * 0.7 * 0.5 * 0.7=0.24 \%$ year bases $=0.12 \%$ per semester.

The above processed coefficient transit allowed the construction of the block diagram model shown in Figure 1.

After defining the transit coefficients, the population dynamics were given by the set of difference equations, expressed as follows. 
This system can be written in a matrix form as follows:

$$
\begin{aligned}
S(n+1)= & S(n)+\beta_{1} N(n)+\alpha_{1}(n-32)-D_{1} \\
& -\gamma_{1 r_{1}}(n)-\beta_{5} S(n), \\
N(n+1)= & N(n)-\beta_{1} N(n)+\alpha_{2}(n-32)-D_{2} \\
& -\gamma_{1 r_{2}}(n)+\beta_{5} S(n)+\beta_{6} \operatorname{AF}(n) \\
& +\gamma_{2} \operatorname{AS}(n)-\beta_{2} N(n)+T, \\
\operatorname{AS}(n+1)= & \operatorname{AS}(n)+\alpha_{3}(n-32)-D_{3}-\gamma_{1 r_{3}}(n) \\
& -\left(\beta_{3}+\beta_{4}\right) \operatorname{AS}(n)-\gamma_{2} \operatorname{AS}(n) \\
& +\beta_{2} N(n)-T, \\
\operatorname{AF}(n+1)= & \operatorname{AF}(n)+\alpha_{4}(n-32)-D_{4}-\gamma_{1 r_{4}}(n) \\
& +\left(\beta_{3}+\beta_{4}\right) \operatorname{AS}(n)-\beta_{6} \operatorname{AF}(n) .
\end{aligned}
$$

With the vector notation,

$$
Z(n+1)=[S(n), N(n), \operatorname{AS}(n), \operatorname{AF}(n)]^{T} .
$$

The previous system of difference equations can be written in vector form as follows:

$$
Z(n+1)=V(E, r) * Z(n)+b(n)
$$

where

$$
\begin{aligned}
V & =\left[\begin{array}{cccc}
1-\beta_{5} & \beta_{1} & 0 & 0 \\
\beta_{5} & 1-\beta_{2} & \gamma_{2} & \beta_{6} \\
0 & \beta_{2} & 1-\gamma_{2}-\beta_{3}-\beta_{4} & 0 \\
0 & 0 & \beta_{3}+\beta_{4} & 1
\end{array}\right], \\
b(n)= & \left\{\begin{array}{l}
\alpha_{1}(n-32)-\gamma_{1 r_{1}}(n)-D_{1} \\
\alpha_{2}(n-32)-\gamma_{1 r_{2}}(n)-D_{2} \\
\alpha_{3}(n-32)-\gamma_{1 r_{3}}(n)-D_{3} \\
\alpha_{4}(n-32)-\gamma_{1 r_{4}}(n)-D_{4}
\end{array}\right\}
\end{aligned}
$$

and where the value of the subpopulations at the start of the period was (see Table 1)

$$
Z(0)=[1,713,051 ; 8,901,145 ; 6,046,061 ; 134,359] .
$$

It is easy to check that an explicit closed form solution of the problem takes the form

$$
Z(n)=V^{n} Z(0)+\sum_{j=0}^{n-1} V^{n-j-1} b(j), \quad 1 \leq n \leq 11
$$

although expression (9) is not necessary to perform the computations of $Z(n)$, for the 11 semesters of the period of study.
TABLE 4: Results of the model that corresponded to $E=0$ and $r=$ $1 / 8$.

\begin{tabular}{lcccc}
\hline & $S$ & $N$ & AS & AF \\
\hline 01-Jan-12 & $1,713,051$ & $8,901,145$ & $6,046,061$ & 134,359 \\
01-Jul-12 & $1,716,898$ & $8,920,041$ & $5,495,299$ & 522,821 \\
01-Jan-13 & $1,719,020$ & $8,889,527$ & $5,047,893$ & 842,092 \\
01-Jul-13 & $1,720,848$ & $8,828,147$ & $4,688,071$ & $1,104,939$ \\
01-Jan-14 & $1,730,442$ & $8,790,242$ & $4,429,615$ & $1,322,814$ \\
01-Jul-14 & $1,739,460$ & $8,735,669$ & $4,223,798$ & $1,505,293$ \\
01-Jan-15 & $1,753,035$ & $8,699,773$ & $4,080,490$ & $1,659,531$ \\
01-Jul-15 & $1,765,928$ & $8,655,552$ & $3,968,615$ & $1,791,344$ \\
01-Jan-16 & $1,778,343$ & $8,610,879$ & $3,884,905$ & $1,905,039$ \\
01-Jul-16 & $1,790,044$ & $8,562,543$ & $3,820,648$ & $2,003,658$ \\
01-Jan-17 & $1,801,107$ & $8,515,530$ & $3,774,027$ & $2,089,996$ \\
01-Jul-17 & $1,811,480$ & $8,467,595$ & $3,739,342$ & $2,166,010$ \\
\hline
\end{tabular}

TABLE 5: Subpopulation results.

\begin{tabular}{lcccc}
\hline & $S$ & $N$ & AS & AF \\
\hline 01-Jan-12 & $10.20 \%$ & $53.00 \%$ & $36.00 \%$ & $0.80 \%$ \\
01-Jul-17 & $11.19 \%$ & $52.32 \%$ & $23.10 \%$ & $13.38 \%$ \\
\hline
\end{tabular}

\section{Results and Simulations}

After we modeled the transit coefficients, the subpopulations were computed by solving the model. Thus by taking $E=0$, which corresponded to the hypotheses of an alcohol rate consumption of $5 \%$ and $r=1 / 8$, we obtained the subpopulation results shown in Table 4 .

As Table 4 shows, the AF subpopulation grew by an average of 200,000 new aggressors each semester until July 2014. Then from July 2014 to July 2017, this growth slowed down to 100,000 new aggressors per semester. The system's initial lack of accuracy due to a poor realistic number of aggressors when only legal complaints were quantified as physical aggressions led to this subpopulation's fast initial growth until the midperiod. Then growth slowed down to approximately half until the end of the period. The subpopulation of regular men was almost stable for the whole study period.

During the considered study period, the proportion of regular and egalitarian men remained fairly stable and changed less than $1 \%$, while AS dropped by $12.90 \%$. In contrast, the AF proportion grew considerably by about $12 \%$ (Table 5).

The trend of the studied subpopulations is shown in Figure 2.

Table 6 shows the variations in populations when the alcohol rates changed from $3 \%$ to $7 \%$. As we can see, the subpopulations of aggressors grew with an increased alcohol rate. For instance, it was relevant that the physical aggressors population grew by about $0.4 \%$ for each $1 \%$ increase in the alcohol rate.

One important issue in the proposed model was the probability of the couple's stability, explained when quantifying $\gamma_{2}$. Thus we modeled the subpopulations trend by varying the $r$-value in July 2017. As Table 7 shows, both physical and 
TABLE 6: Robustness alcohol rate.

\begin{tabular}{lcccc}
\hline Alcohol rate & $S$ & $N$ & AS & AF \\
\hline 3 & $11.28 \%$ & $54.34 \%$ & $21.59 \%$ & $12.79 \%$ \\
4 & $11.23 \%$ & $53.32 \%$ & $22.36 \%$ & $13.09 \%$ \\
5 & $11.19 \%$ & $52.32 \%$ & $23.10 \%$ & $13.38 \%$ \\
6 & $11.15 \%$ & $51.34 \%$ & $23.83 \%$ & $13.68 \%$ \\
7 & $11.11 \%$ & $50.39 \%$ & $24.53 \%$ & $13.97 \%$ \\
\hline
\end{tabular}

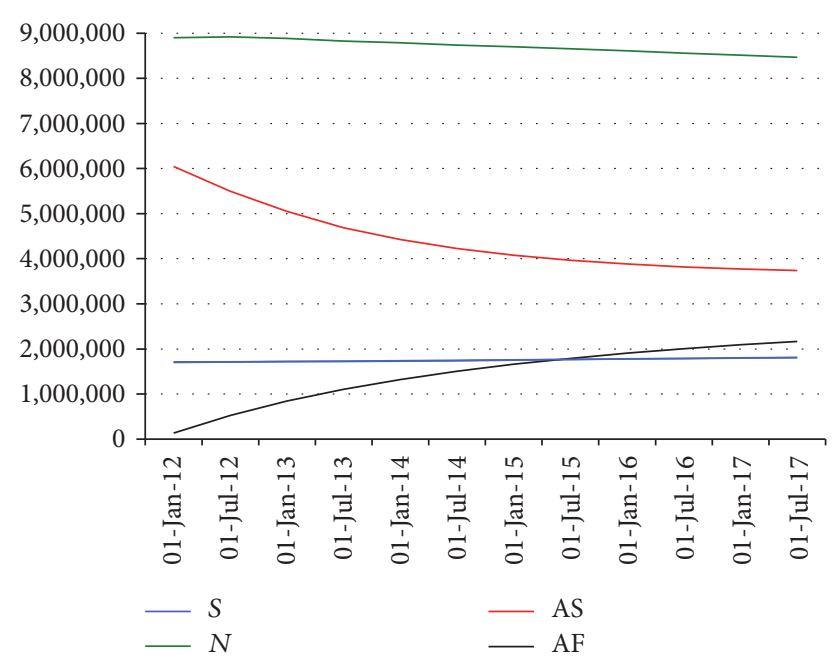

FIgURE 2: Subpopulation trends.

psychological aggressors became most sensitive to variations in this parameter. When the probability of the couple lasting increased, the AF and AS subpopulations reduced. The maximum reduction for the AF and AS proportions occurred when $r=1$ ( $100 \%$ couple stability probability). The reason behind those results was that the transit to AS and AF mainly occurred when the couple broke up, and the level of aggression of the jealous and possessive men against women increased. Thus the smaller the number of couples breaking up, the fewer the aggressive behavior transits.

\section{Conclusions and Recommendations}

Our model quantified the future population of psychological and physical aggressors in Spain by taking into account dynamic factors, such as demographic, economic, and sociocultural (alcohol, drugs, jealousy, marital separations, and poverty index) factors. However, it did not take into account important factors such as genetics and/or legal environments, which most likely had an impact on our results. Data about genetic factors is confidential, while legal environment data can be simulated, but it is a fixed unchangeable factor in location and time period terms.

An important underlying consequence of this study is the prevalent potential and preventive role played by women in each domestic violence event, to the extent that the main recommendation to overcome this dramatic problem lies in women's active decision of breaking up their relationship in
TABLE 7: Sensitivity analysis of the model versus the couple's stability.

\begin{tabular}{ccccc}
\hline$r$ & $S$ & $N$ & AS & AF \\
\hline 1 & $11.11 \%$ & $50.39 \%$ & $24.53 \%$ & $13.97 \%$ \\
2 & $11.52 \%$ & $58.83 \%$ & $18.22 \%$ & $11.43 \%$ \\
4 & $12.08 \%$ & $68.15 \%$ & $11.60 \%$ & $8.17 \%$ \\
6 & $12.41 \%$ & $72.82 \%$ & $8.47 \%$ & $6.29 \%$ \\
8 & $12.64 \%$ & $75.56 \%$ & $6.69 \%$ & $5.12 \%$ \\
\hline
\end{tabular}

early stages of psychological abuse. This long-term recommendation requires strong willpower and Government action by investing in egalitarian education from early stage on childhood.

In the short-term the main recommendation to slow down this dramatic problem is sound and urgent public investment in education and media campaign ( $\mathrm{TV}$, social media, radio, public venues, and advertisements).

From our model, the hidden population of aggressors appears which is not quantified by official statistics and which reveals the problem when it is irreparable. Among the main reasons that explain this situation, we find poor recognition of abusive partners' behaviors in early stages of the relationship, combined with the social shame and low levels of self-esteem experienced by abused women. Lack of security resources (economic, legal protection, housing, and psychological resources) means that women barely report their abusive partners.

One of the advantages of having such a model like that presented herein is that the results can be simulated according to certain parameters, such as level of alcoholism consumption and drug use.

The study can be applied to any other geographical area where data are available, and the study period can be changed. However, it is important to take into account that the longer the study period, the less reliable the obtained results.

\section{Competing Interests}

The authors declare that they have no conflict of interests as to the publication of this paper.

\section{References}

[1] The Convention on the Elimination of All Forms of Discrimination against Women (CEDAW) at United Nations Entity for Gender Equality and The Empowement of Women, http:// www.un.org/womenwatch/daw/cedaw/text/econvention.htm.

[2] S. Todd and L. Colleen, "Framing woman abuse: a structural perspective," in Cruel but Not Usual: Violence in Canadian Families, R. Alaggia and C. Vine, Eds., pp. 327-369, Wilfrid Laurier University Press, Waterloo, Canada, 2006.

[3] K. Connolly, “Cologne inquiry into 'coordinated' New Year's Eve sex attacks," The Guardian, January 2016, http://www .theguardian.com/world/2016/jan/05/germany-crisis-colognenew-years-eve-sex-attacks.

[4] T. Wyke, J. Akbar, U. Andersson, N. Fagge, and S. Malm, "Migrant rape fears spread across Europe: Women told not to go out at night alone after assaults carried out in Sweden, 
Finland, Germany, Austria and Switzerland amid warnings gangs are co-ordinating attacks," January 2016, http://www .dailymail.co.uk/news/article-3390168/Migrant-rape-fears-spreadEurope-Women-told-not-night-assaults-carried-Sweden-FinlandGermany-Austria-Switzerland-amid-warnings-gangs-ordinatingattacks.html.

[5] N. Z. Hilton and G. T. Harris, "Predicting wife assault: a critical review and implications for policy and practice," Trauma, Violence \& Abuse, vol. 6, no. 1, pp. 3-23, 2005.

[6] I. Ruiz-Pérez, J. Plazaola-Castaño, and C. Vives-Cases, "Methodological issues in the study of violence against women," Journal of Epidemiology and Community Health, vol. 61, supplement 2, pp. ii26-ii31, 2007.

[7] W. Fals-Stewart, J. Golden, and J. A. Schumacher, "Intimate partner violence and substance use: a longitudinal day-to-day examination," Addictive Behaviors, vol. 28, no. 9, pp. 1555-1574, 2003.

[8] M. A. Blanco Ruiz, "Implicaciones del uso de las redes sociales en el aumento de la violencia de género en adolescentes," Comunicación y Medios, no. 30, pp. 124-141, 2014 (Spanish).

[9] World Health Organization, Department of Reproductive Health and Research, London School of Hygiene and Tropical Medicine, and South African Medical Research Council, Global and Regional Estimates of Violence against Women: Prevalence and Health Effects of Intimate Partner Violence and Non-Partner Sexual Violence, WHO Press, 2013.

[10] J. B. Kelly and M. P. Johnson, "Differentiation among types of intimate partner violence: research update and implications for interventions," Family Court Review, vol. 46, no. 3, pp. 476-499, 2008.

[11] P. Bordieu, La Dominación Masculina, Editorial Anagrama, Barcelona, Spain, 2000.

[12] World Health Organization, Preventing Intimate Partner and Sexual Violence Against Women. Taking Action and Generating Evidence, World Health Organization, Geneva, Switzerland, 2010.

[13] M. L. Esteban and A. Távora, "El amor romántico y la subordinación social de las mujeres: revisiones y propuestas," Anuario de Psicología, vol. 1, pp. 59-73, 2008.

[14] I. Hyman, S. Guruge, D. E. Stewart, and F. Ahmad, "Primary prevention of violence against women," Women's Health Issues, vol. 10, no. 6, pp. 288-293, 2000.

[15] J. Roehl, C. O’Sullivan, D. Webster, and J. Campbell, "Intimate Partner Violence Risk Assessment Validation Study," National Criminal Justice Reference Service, 2005, https://www.ncjrs.gov/ pdffiles1/nij/grants/209731.pdf.

[16] S. Stith, E. McCollum, and K. Rosen, Couples Therapy for Domestic Violence: Finding Safe Solutions, American Psychological Association, Washington, DC, USA, 2011.

[17] E. Dartnall and R. Jewkes, "Sexual violence against women: the scope of the problem," Best Practice \& Research: Clinical Obstetrics \& Gynaecology, vol. 27, no. 1, pp. 3-13, 2013.

[18] T. K. Humbert, K. Engleman, and C. E. Miller, "Exploring women's expectations of recovery from intimate partner violence: a phenomenological study," Occupational Therapy in Mental Health, vol. 30, no. 4, pp. 358-380, 2014.

[19] Secretaría de Estado de Instituciones Penitenciarias. Estadísticas de Población Penitenciaria (Imprisonned Population Statistics), Ministerio del Interior, Madrid, Spain, 2016, http://institucionpenitenciaria.es/web/portal/documentos/estadisticas.html?r=um \&adm=TES\&am $=2016 \& \mathrm{~mm}=1 \& \mathrm{tm}=\mathrm{TIP} 1 \& \mathrm{tm} 2=\mathrm{GENE}$.
[20] D. Otoo, C. Sebil, and S. K. Amponsah, "Mathematical modeling of domestic violence and its trends, case study Tamale Metropolis, Ghana," Journal of Asian Research, vol. 4, no. 8, pp. 436-447, 2014.

[21] C. Sebel and D. Otoo, "A violence epidemic model to study trend of domestic violence, a study of tamale metropolis," International Journal of Applied Mathematical Research, vol. 3, no. 1, pp. 62-70, 2014.

[22] J. Altrocchi and R. D. Crosby, "Clarifying and measuring the concept of traditional vs. egalitarian roles in marriages," Sex Roles, vol. 20, no. 11-12, pp. 639-648, 1989.

[23] VI Annual Report of the State Women Abuse Obvervatory 2012, Ministry of Health, Social Services and Equality, Spanish Government, 2012 (Spanish).

[24] Violence against women in the judicial statistics: Annual information 2012, General Council of the Judiciary (Spain), Section Judicial Statistics, http://www.poderjudicial.es/cgpj/es/ Temas/Violencia-domestica-y-de-genero/Actividad-del-Observatorio/Datos-estadisticos/?filtroAnio $=2012$.

[25] Salvados, La Sexta, Every day judges dictate 64 restraining orders, Francisca Verdejo, February 2016 (Spanish), http://www lasexta.com/programas/salvados/mejores-momentos/franciscaverdejo-unico-que-soy-consciente-que-voy-encontrar-cuandohablo-mujer-dolor_2016020700130.html.

[26] G. Meil, Analysis of the Survey on Social Perception of Gender Violence, Ministry of Health, Social Services and Equality, Spanish Government, 2011 (Spanish).

[27] G. Meil, Analysis of the Macrosurvey of Gender Violence 2011. Government Delegation for Gender Violence, Ministry of Health, Social Services and Equality, Spanish Government, 2011 (Spanish).

[28] N. Wade, A Troublesome Inheritance: Genes, Race and Human History, Penguin Books, New York, NY, USA, 2014.

[29] I. Rebollo-Mesa, T. Polderman, and L. Moya-Albiol, "Genética de la violencia humana," Revista de Neurologia, vol. 50, no. 9, pp. 533-540, 2010 (Spanish).

[30] Spanish Institute of Statistics, http://www.ine.es/.

[31] M. J. Díaz-Aguado, R. Martínez, and J. Martínez, Evolution of Spanish Teenagers on Equality and Prevention of Gender Violence, Government Delegation for Gender Violence, Ministry of Health, Social Services and Equality, Spanish Government, 2013 (Spanish).

[32] M. Izquierdo, J. F. Jimeno, and A. Lacuesta, "Spain: from immigration to emigration?” Working Paper N1503, EurSpanish Central Bankosystem, Spain, Eurosystem, 2015.

[33] E. Bosch, V. A. Ferrer, V. Ferreiro, and C. Navarro, La Violencia contra las Mujeres. El Amor Como Coartada, Editorial Anthropos, Barcelona, Spain, 2013.

[34] J. Momirow and A. Duffy, Family Violence, A Canadian Introduction, Lorimer, Toronto, Canada, 2011.

[35] I. Márkez, C. Romera, C. Merino et al., "Violencia doméstica, consumo de sustancias y otras circunstancias concurrentes. ¿El derecho versus derecho a la salud?" Revista de la Asociación Española de Neuropsiquiatría, vol. 22, no. 83, pp. 125-133, 2002.

[36] V. A. Ferrer-Pérez and E. Bosch-Fiol, "Gender violence as a social problem in Spain: attitudes and acceptability," Sex Roles, vol. 70, no. 11, pp. 506-521, 2014.

[37] C. Southworth, J. Finn, S. Dawson, C. Fraser, and S. Tucker, "Intimate partner violence, technology, and stalking," Violence Against Women, vol. 13, no. 8, pp. 842-856, 2007. 
[38] B. Perry, Aggression and Violence: The Neurobiology of Experience, http://teacher.scholastic.com/professional/bruceperry/ aggression_violence.htm.

[39] V. Garrido, El Psicópata, Edited by A. Algar, 2000 (Spanish).

[40] I. W. Craig, "The importance of stress and genetic variation in human aggression," BioEssays, vol. 29, no. 3, pp. 227-236, 2007.

[41] M. Castells, Internet y la Sociedad Red, Editorial Alianza, Barcelona, Spain, 2001 (Spanish).

[42] T. K. Logan, J. Cole, and L. Shannon, Partner Stalking: How Women Respond, Cope, and Survive, Springer, New York, NY, USA, 2006. 


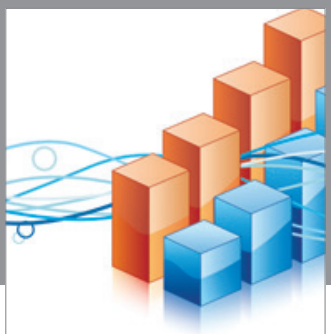

Advances in

Operations Research

vatem alat4

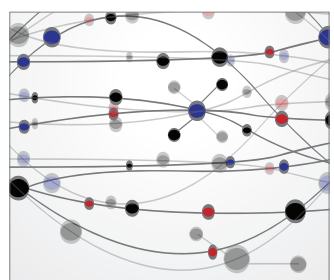

\section{The Scientific} World Journal
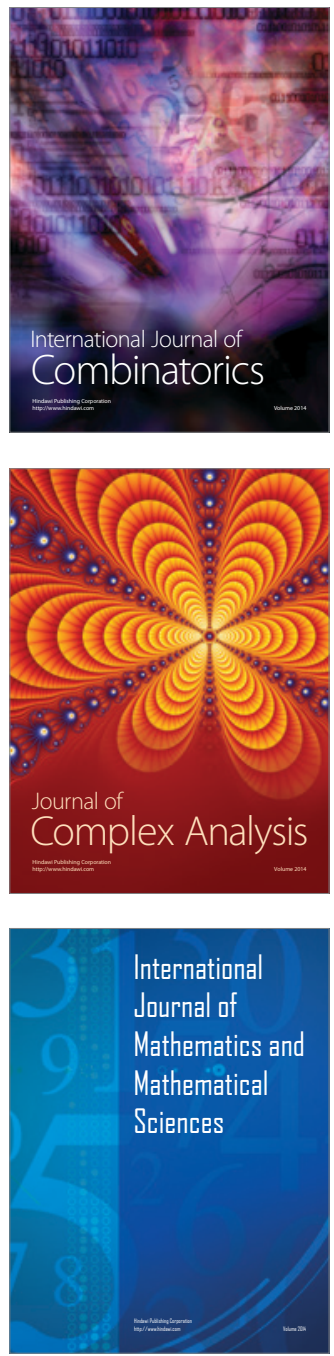
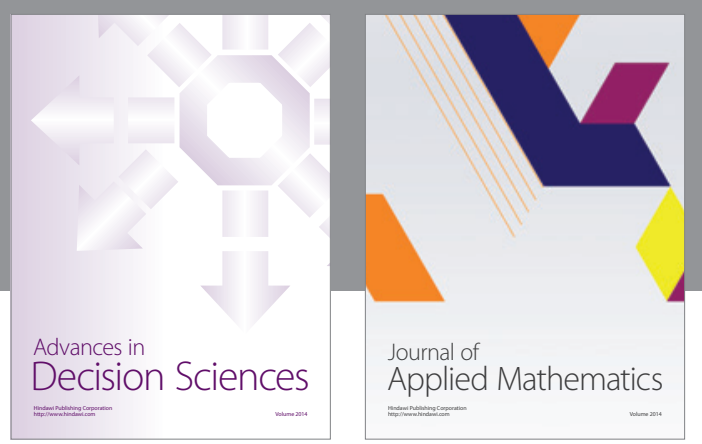

Algebra

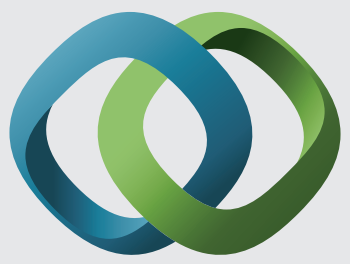

\section{Hindawi}

Submit your manuscripts at

http://www.hindawi.com
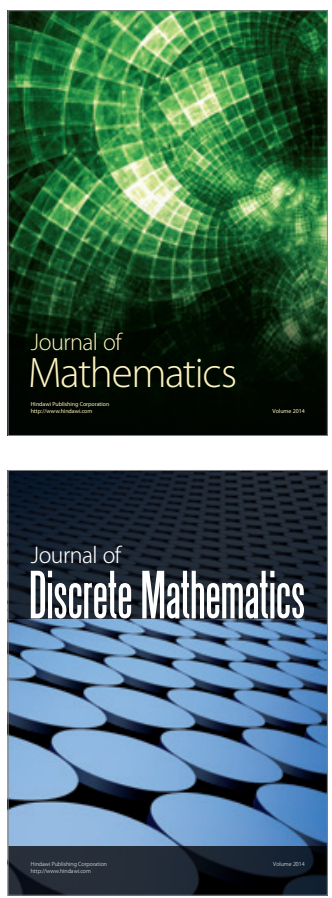

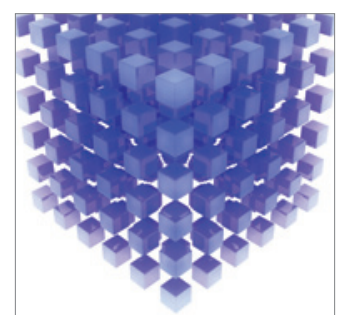

Mathematical Problems in Engineering
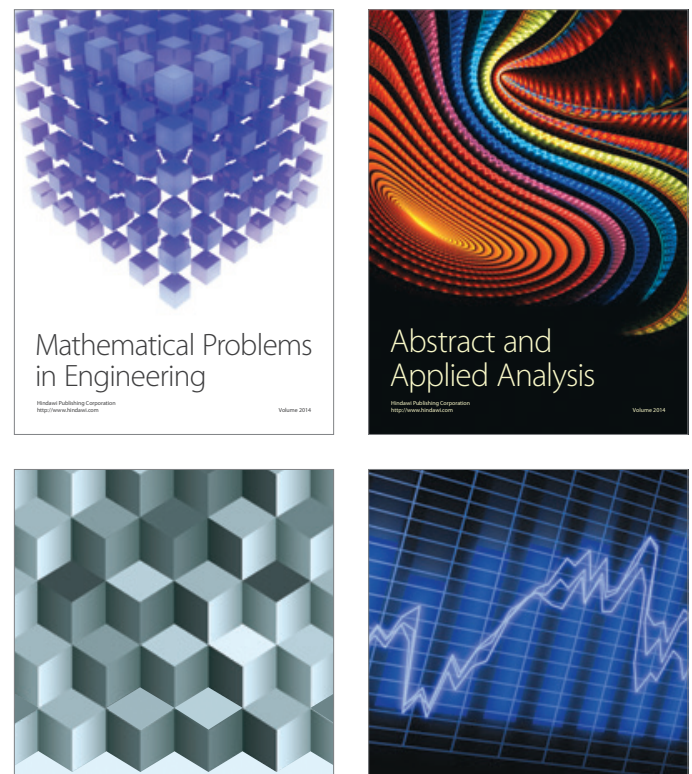

Journal of

Function Spaces

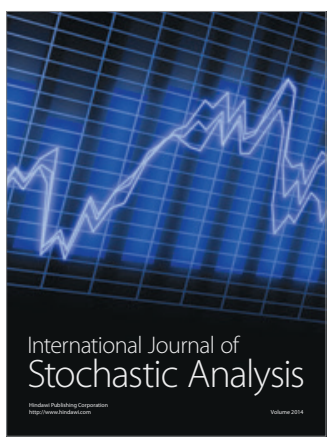

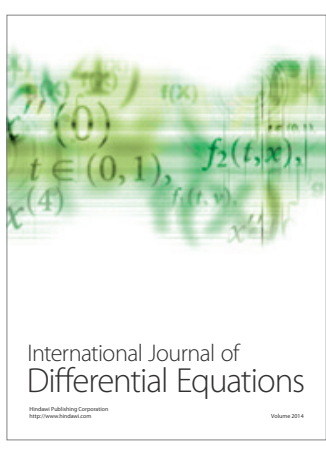
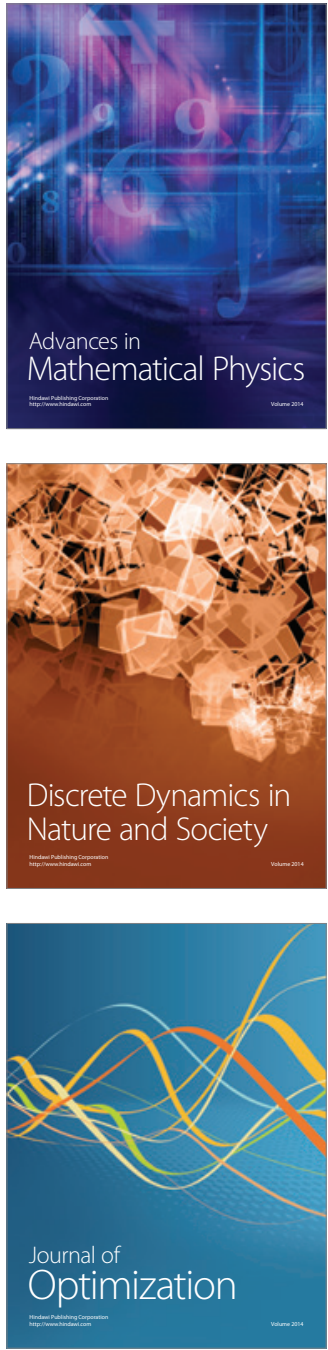